\title{
HILGARDIA
}

A Journal of Agricultural Science Published by the California Agricultural Experiment Station

\section{METHODS OF ESTIMATING CLEAN-FLEECE PRODUCTION}

\author{
G. M. SPURLOCK, STANLEY P. DAVIS, \\ and
}

G. E. BRADFORD 


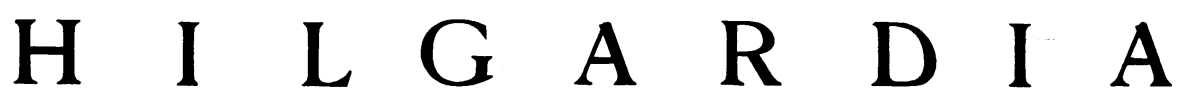

A Journal of Agricultural Science Published by

the California Agricultural Experiment Station

\section{METHODS OF ESTIMATING CLEAN-FLEECE PRODUCTION ${ }^{1}$}

\section{G. M. SPURLOCK, ${ }^{2}$ STANLEY P. DAVIS, ${ }^{3}$ and G. E. BRADFORD ${ }^{4}$}

\section{INTRODUCTION}

ThE DETERmination of clean content of fleeces is subject to a number of sources of error. Among them, in addition to the method of assessment used, are differences in shrinkage, fiber length, grade, defect, and the climate in the area where the fleece was grown.

The Neale squeeze machine (Neale et al., 1956) has been reported to give accurate estimates of clean-wool content of fleeces. It was felt that it would be desirable to test its accuracy on fleeces showing a wider variation in shrinkage and foreign-matter content than those on which the machine had previously been tested, and to compare its accuracy with that of grease weight and the side-sample method. This report contains the results of tests on wool from California and Texas, each state being represented by several widely varying locations.

\section{MATERIALS AND METHODS}

Fleeces from five flocks in five locations in California and from seven flocks in two locations in Texas were used in the study. Two of the California flocks were represented two years, 1958 and 1959. A total of 728 fleeces was involved. Data on lot size, origin, growth period and climatic information on the locations where the fleeces were grown are presented in table 1 .

Three different squeeze machines were used. Six lots were tested on a second machine following the initial test on the first. Both freshly shorn and conditioned wools were tested.

Grease-weight and squeeze readings were recorded for all fleeces. Fleeces from two flocks in California were side sampled during both 1958 and 1959. This sampling procedure consisted of the removal of approximately $100 \mathrm{gm}$ of grease wool from the mid-side of the animal as it was shorn and before the remainder of the fleece was weighed or squeezed. The samples were placed in plastic bags, weighed, scoured and adjusted to standard A.S.T.M. conditions for reweighing. Yield figures based on these samples

\footnotetext{
${ }^{1}$ Submitted for publication November 1, 1961.

${ }^{2}$ Assistant Professor of Animal Husbandry and Assistant Animal Husbandman in the Experiment Station, Davis.

${ }^{8}$ Wool and Mohair Technologist, Texas A \& M College, College Station, Texas.

-Assistant Professor of Animal Husbandry and Assistant Animal Husbandman in the Experiment Station, Davis.
} 
TABLE 1

NUMBER, GROWTH PERIOD AND SOURCE FLOCK LOCATION OF FLEECES USED

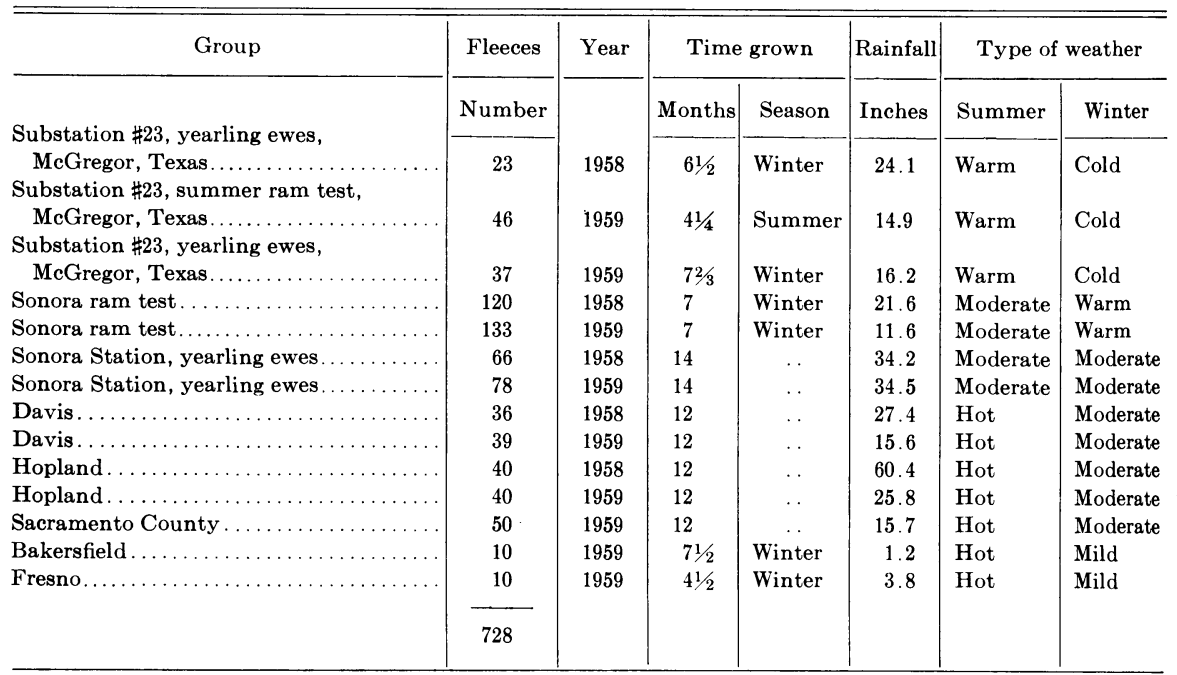

were applied to the grease weight of the remainder of the fleece to give a yield estimate of the entire fleece not including the sample.

All fleeces were scoured in the Wool and Mohair Laboratory, College Station, Texas, where actual clean-fiber content was determined. Side samples were scoured at the University of California, Davis, wool laboratory.

\section{RESULTS AND DISCUSSION}

The means for the items studied, the correlations between these measures and actual clean-fleece weight, and standard errors of estimates are presented in tables 2 and 3.

Where pertinent comparisons are available (Davis and Hopland clips, table 2 ) the side-sample estimate was more accurate than other methods for estimating clean-fleece weight. This is shown by higher correlation values and generally lower standard errors for this measure. Correlation values for the squeeze-machine estimate with actual clean content of fleeces, over all lots, ranged closer to 0.8 than the 0.9 reported by Neale et al. (1956).

Squeeze reading was more accurate at Davis and less accurate for the prediction of clean weight at Hopland than was grease weight. These differences were relatively small, but were consistent over both years. Squeeze reading was much more accurate than grease weight in the fleeces from Bakersfield and Fresno. A study of these results suggests that correlations involving grease weight are subject to wide variations apparently attributable to variation in shrinkage. This might be expected. Correlations involving squeeze reading, however, do not appear subject to this source of variation. 
Results from the Texas wools (table 3 ) show no clear-cut trend in relative accuracy of grease-weight and squeeze reading in predicting clean weight. In four lots, grease weight yielded a higher correlation, and in three, squeeze reading was superior. The standard errors likewise show no consistent trend. As in the California wools, correlations involving squeeze reading were less variable, ranging from -0.76 to -0.88 , whereas the greaseweight correlations ranged from 0.63 to 0.92 . Again low correlations in the latter group were associated with higher shrinkage.

Only one comparison can be made of the results of squeezing freshly shorn and conditioned wools by the same machine. This was the case with the Sonora rams, 1958, where fleeces were squeezed freshly shorn and later, as conditioned wools, by the Texas Wool Laboratory machine. The difference between the two correlations was very small.

Comparison of different machines with different operators on the same wools squeezed in the conditioned state is provided by the Fresno and Bakersfield fleeces (table 2) on which both the California and Texas Wool Laboratory machines were used. The correlations are nearly identical. The 1959 Davis and Hopland clips were squeezed freshly shorn by the California machine and conditioned by the Texas machine. The former was more accurate on Davis wools and the latter more accurate on Hopland wools. The differences are not, however, large enough to provide evidence for a real interaction between these variables.

Correlations and standard errors of estimates indicate no consistent difference in favor of use of the estimated weight from the conversion table of Stauder and Neale (1958) over the actual squeeze reading in either Texas or California wools. Where ranking of animals as to production is the only objective of testing, a conversion table is not necessary. If shrinkage is to be estimated on single fleeces or by sampling large lots of wool, a conversion table will furnish values of actual pounds of clean fiber present. However, accuracy of the squeeze method does not appear to be high enough under many conditions to allow its use in shrinkage determination for sales purposes.

The conversion table given by Stauder and Neale (1958) is based on a nonlinear regression of clean-fleece weight on squeeze reading, with greater change in clean weight per machine unit at lower readings. This table also gives different clean-fleece values, for the same machine readings, for coarser and for finer wools.

The data obtained in this study were examined for curvilinearity of regression of clean-fleece weight on squeeze reading. The regressions from flocks with low clean weights (high squeeze readings) tended to be slightly lower than those from flocks with lower squeeze readings, although to a much lesser degree than found by Stauder and Neale. However, fitting a second order regression to the data, either within flocks or to the total data, resulted in a nonsignificant and extremely small reduction in variation from that remaining after linear regression. Further, the regression values for different grades (grouped by individual spinning counts, or into two groups-58's and coarser, and 60's and finer) did not differ significantly from each other or show a consistent trend, within flocks or over-all. 


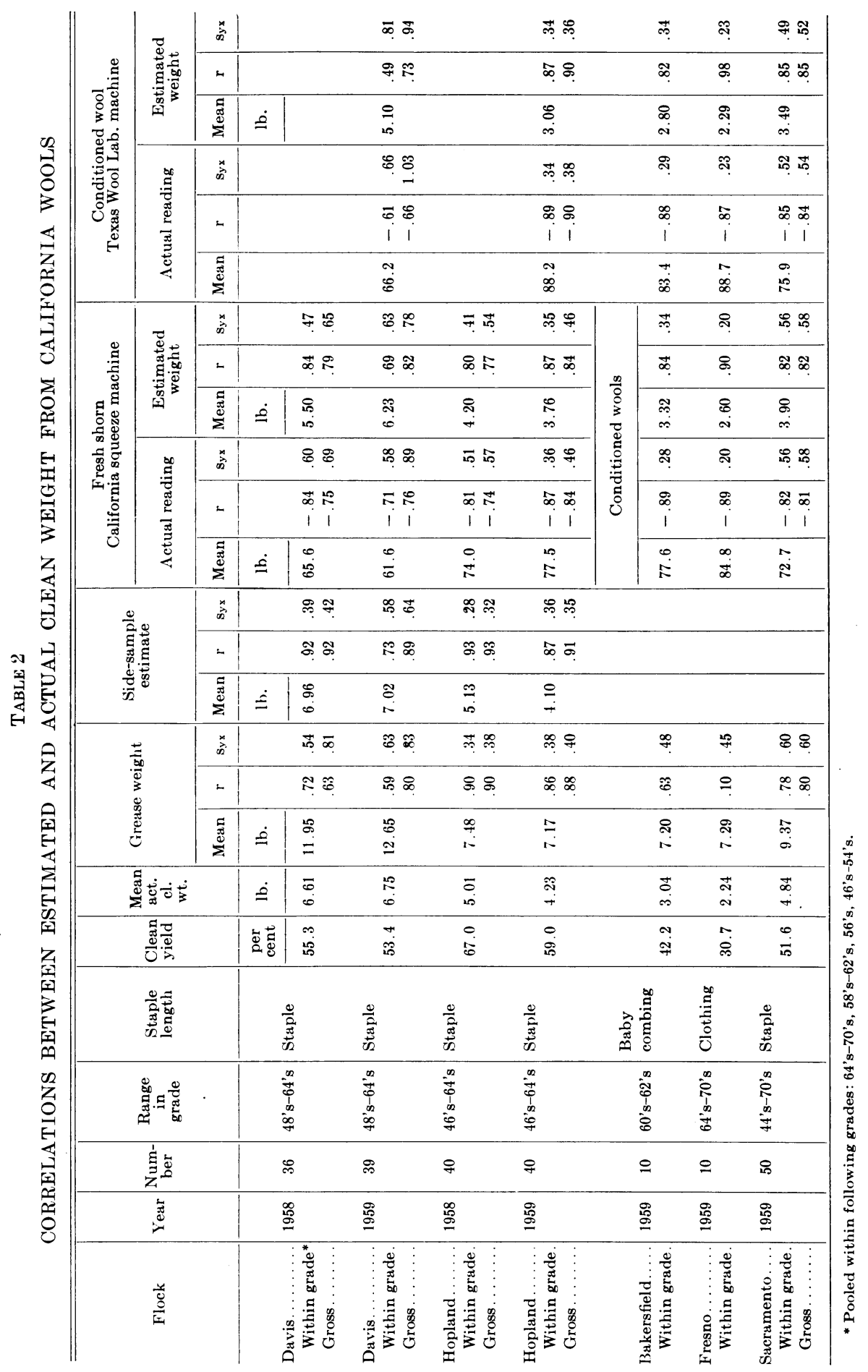




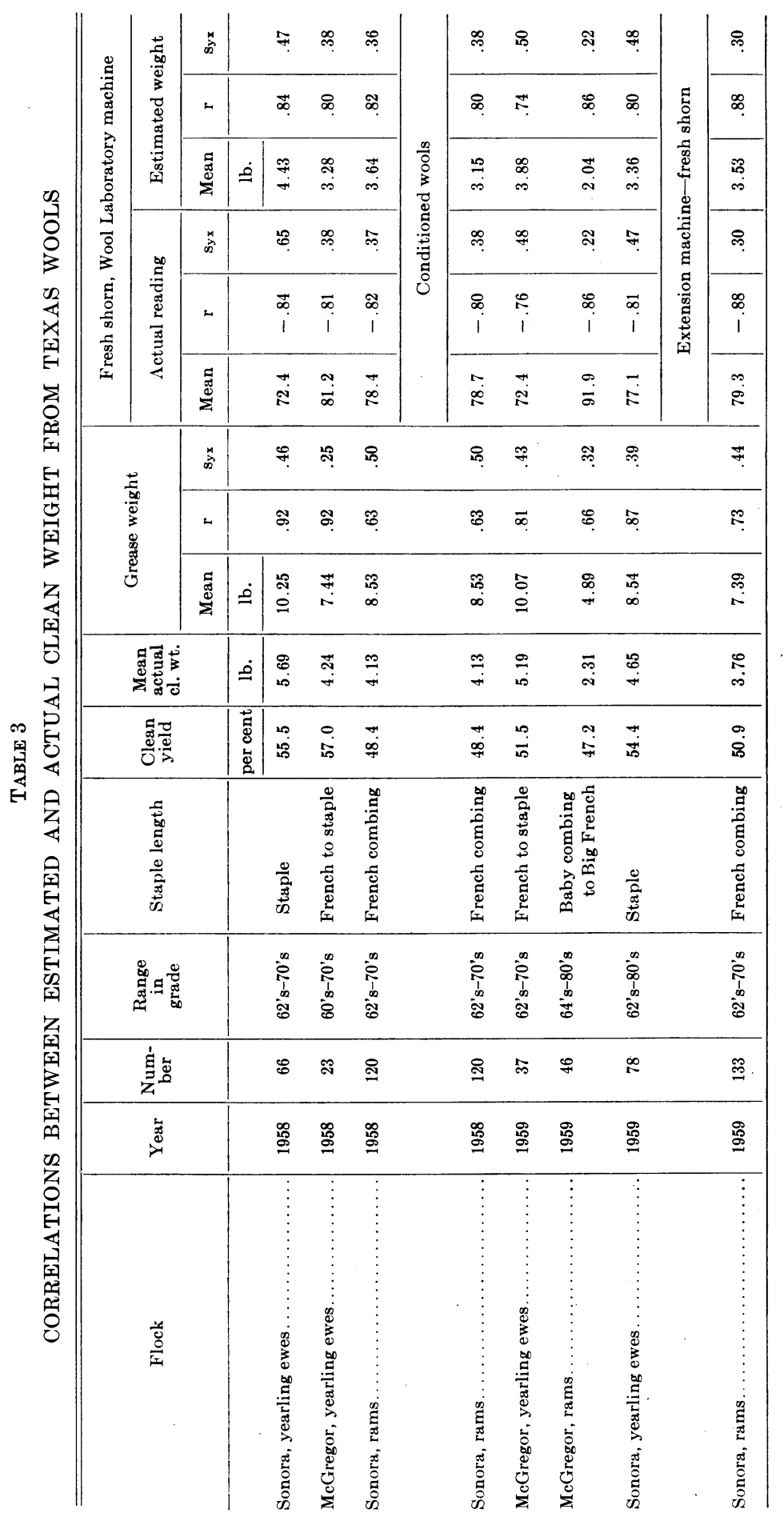


It therefore appears that a linear regression equation based on all the data from this test would be the most satisfactory to use in estimating clean weight from machine readings. The equation obtained in this study, based on data from all fleeces squeezed freshly shorn (497 fleeces) is:

$\mathrm{Y}=16.23-.153 \mathrm{X}$

Where $\mathrm{Y}=$ estimated clean weight

$\mathrm{X}=$ squeeze reading

Sidwell et al. (1958) compared a number of methods of estimating cleanfleece weight. While all methods reported gave reasonably accurate estimates, the squeeze machine method gave a correlation with actual cleanfleece weight of 0.87 and the side-sample method 0.92 .

Price et al. (1960) also compared a number of methods of estimation, including grease weight, side-sample and squeeze reading. These gave correlations ranging from $0.84-0.93,0.88-0.95$, and $0.82-0.87$, respectively. The fleeces graded fine through quarter blood. In the presence of grease-fleece weight these workers found that the contribution of machine reading to their prediction equations was significant only for fine $(\mathrm{P}<0.01), 1 / 2$ blood $(\mathrm{P}<0.05)$ and $3 / 8$ blood $(\mathrm{P}<0.10)$ wools. Staple length made a significant contribution only for the fine-wool equation.

Under practical field conditions, where ease and speed of assessment are important for ranking animals in a flock for selection purposes, the sidesample method is too slow and in most cases cannot be used by the breeder himself. Either grease-weight or squeeze-machine reading are far superior in this regard, and assessment can be made by untrained personnel.

The results of this study indicate little difference in accuracy between these two methods on wools yielding 50 per cent or higher but that the squeeze machine is more accurate on lower-yielding wools.

\section{SUMMARY AND CONCLUSIONS}

A total of 728 fleeces from 12 flocks representing seven locations in California and Texas were used in the evaluation of different methods for assessment of clean-fiber content.

Methods compared with actual clean-fleece weight include side-sample estimate, grease-weight, squeeze-machine reading and estimated weight from squeeze reading.

Side-sample estimate was the most accurate of the methods used. It is also the most laborious. The squeeze-machine reading and estimated weight from squeeze reading were more accurate than grease weight where clean vield was low.

The squeeze machine is a practical tool for use in ranking animals in order of clean-fiber production except with high-yielding wools where the machine may be equaled or surpassed in accuracy by grease weight.

There was little difference in accuracy due to squeezing freshly shorn or conditioned wools, or between different machines and operators.

For obtaining clean-fleece weight from squeeze reading for freshly shorn fleeces, the equation $\mathrm{Y}=16.23-.153 \mathrm{X}$, where $\mathrm{X}$ is squeeze reading and $\mathrm{Y}$ estimated clean-fleece weight in pounds was found to give the best prediction. 


\section{LITERATURE CITED}

NeALe, P. E., and W. D. MCFAddeN

1954. A formula for selection of high producing sheep. New Mexico Agr. Exp. Sta. Press Bull. 1131.

Neale, P. E., George Sidwell and Wm. McFadden

1956. Clean-fleece yield in two minutes. Proc. Ann. Meeting, West. Sect., Amer. Soc. Animal Prod., 7, LXXIV.

Price, D. A., S. K. Ercanbrack and L. O. Wilson

1960. An evaluation of the "squeeze machine" and other methods of estimating cleanfleece weight. Proc. Ann. Meeting, West. Sect., Amer. Soc. Animal Prod., 11, XIV-1.

Sidwell, George M., P. E. Neale and Gordon L. Jessup, Jr.

1958. A comparison of five methods of estimating clean fleece weight. J. Animal Sci. $17: 593-97$.

Stauder, J. R. and P. E. Neale

1958. Selecting range sheep. Agr. Ext. Service, New Mexico A \& M College Cir. 284:1-27. 

The journal Hilgardia is published at irregular intervals, in volumes of about 600 pages. The number of issues per volume varies. Subscriptions are not sold. The periodical is sent as published only to libraries, or to institutions in foreign countries having publications to offer in exchange.

You may obtain a single copy of any issue free, as long as the supply lasts; please request by volume and issue number from:

\author{
Agricultural Publications \\ Room 207 University Hall \\ University of California \\ Berkeley 4, California
}

The limit to nonresidents of California is 10 separate issues on a single order. A list of the issues still available will be sent on request. 